PAPER

\title{
Vestibulo-ocular arreflexia in families with spinocerebellar ataxia type 3 (Machado-Joseph disease)
}

\author{
C R Gordon, V Joffe, G Vainstein, N Gadoth
}

J Neurol Neurosurg Psychiatry 2003;74:1403-1406

See end of article for authors' affiliations

.....................

Correspondence to:

Dr C R Gordon

Department of Neurology,

Meir General Hospital,

Kfar Saba 44281, Israel;

cgordon@post.tau.ac.il

Received 8December 2002

In revised form

1 March 2003

Accepted 4 March 2003

\begin{abstract}
Objective: To identify the presence of vestibulo-ocular arreflexia in patients with Machado-Joseph disease (MJD), which can easily be diagnosed at the bedside.

Methods: Seven patients with MJD from five unrelated families and 11 patients with sporadic or hereditary cerebellar ataxia other than MJD underwent a detailed neuro-otological and oculomotor examination. Six MJD and five non-MJD patients also underwent electro-oculographic recordings and caloric tests.

Results: Gaze evoked nystagmus, smooth pursuit, and saccade abnormalities were found in both MJD and non-MJD patients. However, in all seven MJD patients but in none of the non-MJD patients, sudden passively induced head thrust to both sides elicited pathological corrective catch-up saccades, indicating bilateral loss of the horizontal vestibulo-ocular reflex. This was further confirmed in six MJD patients who had absent vestibular response to both a standard caloric test and ice water ear irrigation. Nystagmus was induced by standard caloric irrigation in all non-MJD patients examined. There was no correlation between the loss of vestibular function and the severity of cerebellar impairment.

Conclusions: The presence of vestibulo-ocular arreflexia, as measured by the head thrust test in a patient with dominant cerebellar ataxia, strongly suggests the diagnosis of MJD.
\end{abstract}

S pinocerebellar ataxia type 3 (SCA3), also known as Machado-Joseph disease (MJD), is the most common form of autosomal dominant cerebellar ataxia. ${ }^{12}$ Although all forms of hereditary spinocerebellar ataxia are the result of multisystem degeneration with widespread neurological impairment, there is sparse information on a specific involvement of the vestibular system. Despite the fact that several reports concerning vestibular hypofunction in patients with MJD were published both before and after genetic testing became available, the concept of vestibular dysfunction in MJD is not widely accepted. . $^{3-5}$

In Israel we have described a Yemenite Jewish genetic isolate of MJD which was characterised by a relatively large number of homozygotes for the CAG trinucleotide repeat expansion at the MJDl gene. ${ }^{67}$

The present report describes vestibulo-ocular arreflexia in patients with MJD, which can easily be diagnosed at the bedside and used in planning genetic studies in patients with autosomal dominant cerebellar ataxia.

\section{METHODS}

Seven patients with MJD from five unrelated families, seven patients with autosomal dominant cerebellar ataxia other than MJD, and four patients with sporadic forms of cerebellar ataxia agreed to participate in the study (tables 1 and 2). All patients with genetically proven MJD were of Jewish-Yemenite extraction. The non-MJD group consisted of three patients with familial episodic ataxia type 2 (EA-2), two with SCA6, two with undiagnosed autosomal dominant cerebellar ataxia, and four with sporadic cerebellar ataxia. In the last six patients, SCA1, 3, 6, and 7, dentatorubropallidoluysian atrophy (DRPLA), vitamin E deficiency, and coeliac disease were ruled out.

All subjects (MJD and non-MJD) had a negative past history for vertigo or hearing impairment. Only one MJD patient reported transient oscillopsia during locomotion or riding in a car. Five MJD patients underwent pure tone audiometry, which was normal.
Following a complete neurological examination, each patient had a detailed oculomotor and neuro-otological examination according to Zee and Fletcher. ${ }^{8}$ This included:

- eye movement testing (alignment, range of motion, vergence, saccades, smooth pursuit, optokinetic nystagmus, and visual cancellation of the vestibulo-ocular reflex (VOR);

- evaluation of spontaneous nystagmus with and without visual fixation (using Frenzel lenses and ophthalmoscopy with the other eye occluded to prevent fixation);

- evaluation of dynamic VOR function (dynamic visual acuity, head thrust, or impulse test, ophthalmoscopy during head shaking, and head shaking nystagmus test).

Eye movement and head thrust tests were videotaped and further evaluated by several experienced independent observers. The head thrust test was done in the sitting position. The patient was asked to fixate his/her gaze on a target about three metres away. The examiner, while facing the patient and holding their head, executed sudden, rapid, unpredictable, angular head rotation to both sides. Abnormal response was determined when head thrust elicited consistent, clinically evident, corrective, catch-up saccades in the opposite direction to the head turn. A normal response was determined when gaze remained fixed on the target with no evidence of eye movement in space.

The severity of cerebellar dysfunction was graded in each patient according to the international ataxia score. ${ }^{9}$ The total ataxia rating score is the sum of posture and gait, kinetic, dysarthria, and oculomotor scores. The oculomotor score include: gaze evoked nystagmus (graded from 0 to 3 ),

Abbreviations: $A D C A$, autosomal dominant cerebellar ataxia; DRPLA, dentatorubropallidoluysian atrophy; MJD, Machado-Joseph disease; MVN, medial vestibular nucleus; NPH, nucleus prepositus hypoglossi; SCA, spinocerebellar ataxia; VOR, vestibulo-ocular reflex 
Table 1 Clinical and genetic features of patients with Machado-Joseph disease

\begin{tabular}{lllllllll}
\hline $\begin{array}{l}\text { Patient/ } \\
\text { sex }\end{array}$ & $\begin{array}{l}\text { Age at } \\
\text { onset }(\mathbf{y})\end{array}$ & $\begin{array}{l}\text { Age at } \\
\text { examination } \\
\text { (y) }\end{array}$ & $\begin{array}{l}\text { Ataxia rating } \\
\text { score (total) }\end{array}$ & $\begin{array}{l}\text { Posture } \\
\text { and gait } \\
\text { score }\end{array}$ & $\begin{array}{l}\text { Kinetic } \\
\text { score }\end{array}$ & $\begin{array}{l}\text { Dysarthria } \\
\text { score }\end{array}$ & $\begin{array}{l}\text { Oculomotor } \\
\text { score }\end{array}$ & $\begin{array}{l}\text { CAG } \\
\text { repeat } \\
\text { length }\end{array}$ \\
\hline $1 / \mathrm{M}$ & 28 & 36 & $45 / 100$ & $24 / 34$ & $11 / 52$ & $5 / 8$ & $5 / 6$ & $23 / 76$ \\
$2 / M^{*}$ & 44 & 59 & $63 / 100$ & $30 / 34$ & $23 / 52$ & $5 / 8$ & $5 / 6$ & $28 / 70$ \\
$3 / M^{*}$ & 40 & 46 & $20 / 100$ & $7 / 34$ & $7 / 52$ & $2 / 8$ & $4 / 6$ & $23 / 70$ \\
$4 / \mathrm{F}$ & 36 & 43 & $29 / 100$ & $14 / 34$ & $8 / 52$ & $2 / 8$ & $5 / 6$ & $65 / 66$ \\
$5 / M^{* *}$ & 51 & 59 & $27 / 100$ & $9 / 34$ & $13 / 52$ & $3 / 6$ & $2 / 8$ & $28 / 68$ \\
$6 / M^{* *}$ & 34 & 42 & $48 / 100$ & $13 / 34$ & $28 / 52$ & $4 / 6$ & $3 / 8$ & $13 / 75$ \\
$7 / M^{* *}$ & 28 & 40 & $72 / 100$ & $30 / 34$ & $33 / 52$ & $5 / 6$ & $4 / 8$ & $25 / 75$ \\
\hline
\end{tabular}

*Brothers; ${ }^{* *}$ cousins

$F$, female; $M$, male; $y$, years.

abnormalities of the ocular pursuit (from 0 to 2), and dysmetria of the saccade (from 0 to 1 ).

Six of the MJD patients underwent conventional dc electronystagmography including standard bithermal caloric test and ice water ear irrigation. Each ear was irrigated in turn with water at $30^{\circ} \mathrm{C}$ and $44^{\circ} \mathrm{C}$ from a closed loop system. For the ice test (irrigation at $0^{\circ} \mathrm{C}$ ), the ear was syringed with $50 \mathrm{ml}$ of ice water. Five non-MJD patients underwent standard bithermal caloric testing.

\section{RESULTS}

Various degrees of gaze evoked nystagmus, smooth pursuit, and saccade abnormalities were found in both groups. In the seven patients with MJD but in none without MJD, sudden passively induced head thrust to both sides elicited corrective catch-up saccades, indicating bilateral loss of the horizontal VOR (see video recording of the two patients with MJD on the JNNP website). When patients with MJD were asked to shake their head at a frequency of about $2 \mathrm{~Hz}$ while reading the Snellen visual acuity chart (dynamic visual acuity test), there was a fall in acuity of more than two lines. Also, on ophthalmoscopy the image of the optic disc was unstable during head shaking. In all patients the optic disc moved opposite to the direction of the head, indicating a hypoactive or non-acting reflex. In two of the non-MJD patients an abnormal dynamic visual acuity test was present, while in three the optic disc image was unstable while shaking their heads during ophthalmoscopy. In these three cases, the optic disc moved with the head, indicating a hyperactive VOR.

In five of the six MJD patients who underwent standard caloric tests and ice water irrigation, no nystagmus was elicited and they did not experience any dizziness or vertigo.
In the sixth patient-the only one who reported on transient oscillopsia during locomotion or riding in a car-nystagmus was detected when he was asked to open his eyes one minute after the completion of ear irrigation. During this paradoxical caloric response he experienced mild vertigo. In the five nonMJD patients standard caloric testing elicited nystagmus. The presence of caloric induced nystagmus made the irrigation of ice water unnecessary.

Vestibular arreflexia was unrelated to the severity of cerebellar dysfunction as it was present in patients 3 to 5 who were relatively mildly affected.

\section{DISCUSSION}

This study shows that the vestibulo-ocular reflex is deficient or absent in Yemenite Jewish patients with MJD. This finding was unique to MJD and was not present in patients without MJD.

Vestibulo-ocular arreflexia was easily diagnosed at the bedside with the head thrust or impulse test. This test was originally described as a simple and reliable clinical sign of total unilateral loss of horizontal semicircular canal function. ${ }^{10}$ The principle guiding the testing of VOR using rapid head turns is that these thrust are too fast to allow vision to contribute to the response. Thus an inadequate vestibular response will elicit clinically evident corrective saccade if the eye is no longer on target after the head rotation. The validity of this clinical sign as an indicator of vestibular loss has been systematically studied by recording eye movements using magnetic search coils. ${ }^{11-13}$

In line with the presence of vestibular arreflexia, all patients with MJD had an abnormal dynamic visual acuity test and the optic disc image was unstable when shaking

Table 2 Clinical features of patients with non-Machado-Joseph disease cerebellar ataxia

\begin{tabular}{|c|c|c|c|c|c|c|c|}
\hline $\begin{array}{l}\text { Patient/ } \\
\text { sex }\end{array}$ & $\begin{array}{l}\text { Age at } \\
\text { onset (y) }\end{array}$ & $\begin{array}{l}\text { Age at } \\
\text { examination } \\
\text { (y) }\end{array}$ & $\begin{array}{l}\text { Ataxia rating } \\
\text { score (total) }\end{array}$ & $\begin{array}{l}\text { Posture and } \\
\text { gait score }\end{array}$ & $\begin{array}{l}\text { Kinetic } \\
\text { score }\end{array}$ & $\begin{array}{l}\text { Dysarthria } \\
\text { score }\end{array}$ & $\begin{array}{l}\text { Oculomotor } \\
\text { score }\end{array}$ \\
\hline $1 \mp / M^{*}$ & 30 & 51 & $48 / 100$ & $19 / 34$ & $19 / 52$ & $5 / 8$ & $5 / 6$ \\
\hline $2 / M^{*}$ & 17 & 24 & $15 / 100$ & $5 / 34$ & $3 / 52$ & $2 / 8$ & $5 / 6$ \\
\hline $3 \ddagger / F^{* *}$ & 2 & 24 & $4 / 100$ & $0 / 34$ & $0 / 52$ & $0 / 8$ & $4 / 6$ \\
\hline $4 / F^{* *}$ & $?$ & 46 & $3 / 100$ & $0 / 34$ & $0 / 52$ & $0 / 8$ & $3 / 6$ \\
\hline $5 / F^{* *}$ & 20 & 55 & $3 / 100$ & $0 / 34$ & $0 / 52$ & $0 / 8$ & $3 / 6$ \\
\hline $6 \pm / F^{* * *}$ & 38 & 66 & $74 / 100$ & $28 / 34$ & $36 / 52$ & $5 / 8$ & $5 / 6$ \\
\hline $7 \ddagger / F^{* * *}$ & 25 & 42 & $51 / 100$ & $16 / 34$ & $26 / 52$ & $4 / 8$ & $5 / 6$ \\
\hline $8 \mp / F \dagger$ & 20 & 41 & $70 / 100$ & $29 / 34$ & $32 / 52$ & $3 / 8$ & $6 / 6$ \\
\hline $9 / \mathrm{Ft}$ & 30 & 32 & $11 / 100$ & $3 / 34$ & $6 / 52$ & $0 / 8$ & $2 / 6$ \\
\hline 10/M+ & 74 & 76 & $37 / 100$ & $10 / 34$ & $20 / 52$ & $5 / 8$ & $2 / 6$ \\
\hline $11 / \mathrm{Ft}$ & 20 & 45 & $25 / 100$ & $9 / 34$ & $10 / 52$ & $1 / 8$ & $5 / 6$ \\
\hline
\end{tabular}

*Undiagnosed autosomal dominant cerebellar ataxia.

**Familial episodic ataxia type 2 (EA-2).

***Spinocerebellar ataxia type 6 (SCA6)

†Sporadic cerebellar ataxia.

tPatients who underwent a standard caloric test.

$F$, female; $M$, male; $y$, years. 
their heads during ophthalmoscopy. Interestingly, only one patient reported oscillopsia during locomotion or riding in a car. It is probable that long term vestibular loss in our patients with MJD is compensated by suppression of the perception of oscillopsia, use of effort to localise a target in space, preprogramming of compensatory slow eye movements, and restriction of movement of the head. Those and other adaptive mechanisms have been described in patients with bilateral peripheral vestibular loss who reported a decrease in oscillopsia or even denied its presence with time. ${ }^{14}$ All non-MJD patients had a normal head thrust test, while two patients with mild oscillopsia had an abnormal dynamic visual acuity test. They, together with an additional patient, had an unstable optic disc image when shaking their heads during ophthalmoscopy. These clinical findings in non-MJD patients could be explained by hyperactive VOR, which has been reported in cerebellar disorders. ${ }^{15}$

The presence of a hypopactive vestibular caloric response has been suggested in earlier reports of MJD, before the availability of molecular genetic diagnosis. ${ }^{3-5} 16$

All our MJD patients had absent caloric responses to both standard and ice water irrigation, while caloric induced nystagmus was present in all five non-MJD patients. In only one MJD patient was paradoxical appearance of nystagmus detected; this was when, according to the electronystagmography protocol, he was asked to open his eyes one minute after the completion of ear irrigation. This feature, along with the presence of failure of fixation suppression of caloric nystagmus, is considered a sign of central vestibulocerebellar dysfunction. ${ }^{17}$

In genetically confirmed autosomal dominant cerebellar ataxia (ADCA) type 1 (SCA1, SCA2, SCA3/MJD), different oculomotor abnormalities-especially saccade accuracy, saccade velocity, and gaze evoked nystagmus-were recorded for each mutation. It was suggested that such data may be of help in choosing the appropriate genetic test. ${ }^{18}{ }^{19}$ In a further study on oculomotor functions in patients with ADCA type $1,{ }^{20}$ the VOR gain measured by post-rotatory nystagmus was significantly reduced in SCAl and SCA3. The severity of vestibular impairment in SCA3 was positively correlated with CAG repeat length. In addition, a reduced response to caloric stimulation was found in all three mutations of ADCA type 1. In an attempt to quantify the oculomotor features of common SCA syndromes, Buttner et al measured the VOR with passive sinusoidal rotation at 0.05 and $0.4 \mathrm{~Hz}$ (peak velocity, 60\% and $30 \%$, respectively). ${ }^{21}$ The gain of the VOR was moderately reduced in SCA3 while it was normal in SCAl, 2, and 6. However, in all these studies, no definite clinical distinction could be made between the three genotypes as there was considerable overlap. It should be noted that the technique and stimulus of the head thrust test used in our patients are essentially different from those used in the above studies. ${ }^{22}$ The caloric and rotational tests used in those studies measure vestibular responses to low frequency stimuli elicited by unnatural conditions, while the head thrust test measures high frequency/high acceleration stimuli (faster than $1 \mathrm{~Hz}$, peak head velocity $150-250 \%$, peak head acceleration $1500-3000 \% \mathrm{~s}^{2}$ ), which are more similar to the head perturbations that occur during everyday activities.

The presence of an abnormal bilateral head thrust test in all our patients with MJD was unrelated to the severity of cerebellar ataxia. We were unable to establish if there is a correlation between cerebellar ataxia score and expansion length because of the uniformity of the CAG expansion length (66-76 repeats) in our patients.

We have not been able to find a description of a positive head thrust test in cerebellar or central vestibular lesions. As all clinical signs of our patients could be attributed to the known central nervous system pathology present in MJD, and they had no symptoms and signs of auditory nerve impairment, we may assume that the loss of vestibular responses in our patients is of central origin. Only a central lesion in the form of selective bilateral degeneration of the medial vestibular nucleus (MVN) and nucleus prepositus hypoglossi (NPH), the site of the so called neural integrator and velocity storage mechanism, can account for central vestibular arreflexia. ${ }^{23}$

Interestingly, in Wernicke's encephalopathy, where lesions in both the medial vestibular nucleus and the NPH are present, ${ }^{24}$ vestibular arreflexia was documented by both caloric and rotational tests. ${ }^{25}$ Lesions in MVN/NPH cause also gaze evoked nystagmus, which was present in all our patients with MJD. Reduced or absent caloric responses have been reported in Friedreich's ataxia ${ }^{26}{ }^{27}$ and is most probably explained by peripheral vestibular damage. ${ }^{15}$ However, neuronal loss and gliosis in the vestibular nucleus was documented in few cases. ${ }^{28}$

Neuronal degeneration in MJD is localised mainly to the dentate, pontine, and cranial nerve nuclei, with preservation of the inferior olivary nucleus and Purkinje cells, ${ }^{29}{ }^{30}$ while involvement of the vestibular nucleus has been mentioned in some cases. Sequeiros and Coutinho ${ }^{31}$ reviewed the neuropathological findings of 18 necropsies designated as clinical MJD, which were collected from the world literature until 1990. All eight cases in whom vestibular nuclei were mentioned were considered "affected". Moreover, these investigators considered the involvement of the vestibular nuclei to be one of the neuropathological criteria for MJD. Yuasa et al found moderate degeneration of the VIIIth cranial nerve nucleus in a patient with a clinical diagnosis of MJD. ${ }^{32}$ Murofushi et al reported on moderate to severe gliosis of the vestibular nuclei in two patients with MJD who had no molecular genetic studies. ${ }^{5}$ Both had absent caloric induced nystagmus. In a recent study, Kumada et al reported on lesions in "pontine and cranial nerve nuclei" in six patients with MJD, three with genetic confirmation..$^{33}$ However, they failed to mention which cranial nerve or pontine nuclei were affected. In six patients with DRPLA, the cranial nerve nuclei were not affected.

Based on the previously reported neuropathological data and our clinical findings we suggest that special emphasis should be placed on the neuropathology of the nucleus prepositus hypoglossi and the vestibular nuclei in patients with genetically proven MJD.

Despite the advance of modern genetic tests, a precise clinical approach to cerebellar ataxias is sometimes difficult because of the overlap of clinical manifestations of the different genotypes. Thus a search for a specific clinical sign that could point to a precise diagnosis in a patient with cerebellar ataxia is worthwhile.

Although our control group was small and included SCA-6, EA-2, and genetically undefined autosomal dominant ataxia in addition to sporadic ataxia, our observation of bilateral vestibular arreflexia documented by the head thrust test in patients with dominant cerebellar ataxia strongly suggests the diagnosis of MJD.

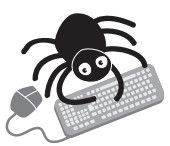

A video recording of two patients with MJD can be seen on the JNNP website at www.jnnp.com/supplemental.

\footnotetext{
Authors' affiliations

C R Gordon, V Joffe, G Vainstein, N Gadoth, Department of Neurology, Meir General Hospital, Kfar Saba and Sackler Faculty of Medicine, Tel Aviv University, Israel

Competing interests: none declared
} 


\section{REFERENCES}

1 Higgins JJ, Nee LE, Vasconcelos $\mathrm{O}$, et al. Mutations in American families with spinocerebellar ataxia (SCA) type 3: SCA3 is allelic to Machado-Joseph disease. Neurology 1996;46:208-13.

2 Silveira I, Lopes-Cendes I, Kish S, et al. Frequency of spinocerebellar ataxia type 1, dentatorubropallidoluysian atrophy, and Machado-Joseph disease mutations in a large group of spinocerebellar ataxia patients. Neurology 1996;46:214-18.

3 Dawson DM, Feudo P, Zubick HH, et al. Electro-oculographic findings in Machado-Joseph disease. Neurology 1982;32:1272-6.

4 Mallinson Al, Longridge NS, McLeod PM. Machado-Joseph disease: the vestibular presentation. J Otolaryngol 1986;15:184-8.

5 Murofushi T, Mizuno M, Hatashida T, et al. Neuro-otological and neuropathological findings in two cases with Machado-Joseph disease. Acta Otolaryngol (Stockh) 1995;520(suppl): 136-9.

6 Goldberg-Stern H, D'jaldetti R, Melamed E, et al. Machado-Joseph (Azorean) disease in a Yemenite family in Israel. Neurology 1994;44:1298-301.

7 Lerer I, Merims D, Abeliovich D, et al. Machado-Joseph disease: correlation between clinical features, the CAG repeat length and homozygosity for the mutation. Eur J Hum Genet 1996:4:3-7.

8 Zee DS, Fletcher WA. Bedside examination. In: Baloh RW, Halmagyi GM, eds. Disorders of the vestibular system. New York: Oxford University Press, 1996: 178-90

9 Trouillas $\mathbf{P}$, Takayanagi $T$, Hallett $M$, et al. International cooperative ataxia rating scale for pharmacological assessment of the cerebellar syndrome. The ataxia neuropharmacology committee of the World Federation of Neurology. J Neurol Sci 1997; 145:205-11.

10 Halmagyi GM, Curthoys IS. A clinical sign of canal paresis. Arch Neurol 1988;45:737-9.

11 Halmagyi GM, Curthoys IS, Cremer PD, et al. The human horizontal vestibuloocular reflex in response to high acceleration stimulation before and after unilateral neurectomy. Exp Brain Res 1990;81:479-90.

12 Aw ST, Halmagyi GM, Haslwanter T, et al. Three-dimensional vector analysis of the human vestibuloocular reflex in response to high-acceleration head rotations. II.Responses in subjects with unilateral vestibular loss and selective semicircular canal occlusion. J Neurophysiol 1996;76:4021-30.

13 Cremer PD, Halmagyi GM, Aw ST, et al. Semicircular canal plane head impulses detect absent function of individual semicircular canals. Brain 1998:121:699-716.

14 Grunfeld EA, Morland AB, Bronstein AM, et al. Adaptation to oscillopsia. A psychophysical and questionnaire investigation. Brain 2000;123:277-290.

15 Moschner C, Perlman S, Baloh RW. Comparison of oculomotor findings in the progressive ataxia syndromes. Brain 1994;117:15-25.
16 Shimizu N, Takiyama Y, Mizuno Y, et al. Characteristics of oculomotor disorders of a family with Joseph's disease. J Neurol 1990;237:393-8.

17 Coats AC. Central electronystagmographic abnormalities. Arch Otolaryngol 1970;92:43-53.

18 Rivaud-Pechoux S, Dürr A, Gaymard B, et al. Eye movement abnormalities correlate with genotype in autosomal dominant cerebellar ataxia type I. Ann Neurol 1998;43:297-302.

19 Bürk K, Abele M, Fetter M, et al. Autosomal dominant cerebellar ataxia type I. Clinical features and MRI in families with SCA1, SCA2 and SCA3. Brain 1996; 1 19:1497-505.

20 Bürk K, Fetter M, Abele M, et al. Autosomal dominant cerebellar ataxia type I: oculomotor abnormalities in families with SCA1, SCA2, and SCA3. J Neurol 1999;246:789-97.

21 Buttner N, Geschwind D, Jen JC, et al. Oculomotor phenotypes in autosomal dominant ataxias. Arch Neurol 1998;55:1353-7.

22 Leigh RJ, Brandt T. A reevaluation of the vestibulo-ocular reflex: new ideas of its purpose, properties, neural substrate, and disorders. Neurology 1993;43:1288-95.

23 Leigh RJ, Zee DS. The neurology of eye movements, 3rd ed. New York: Oxford University Press, 1999.

24 Victor M, Adams RD, Collins GH. The Wernicke-Korsakoff syndrome. Philadelphia: F A Davis Co, 1971 .

25 Furman JMR, Becker JT. Vestibular responses in Wernicke's encephalopathy. Ann Neurol 1989:26:669-74.

26 Baloh RW, Konrad HR, Honrubia V. Vestibulo-ocular function in patients with cerebellar atrophy. Neurology 1975;25:160-8,

27 Ell J, Prasher D, Rudge P. Neuro-otological abnormalities in Friedreich's ataxia. J Neurol Neurosurg Psychiatry 1984;47:26-32.

28 Oppenheimer DR. Brain lesions in Friedreich's ataxia. Can J Neurol Sci 1979;6:173-6.

29 Koeppen AH. The hereditary ataxias. I Neuropathol Exp Neurol 1998;57:531-43.

30 Koeppen AH, Dickson AC, Lamarche JB, Robitaille Y. Synapses in the hereditary ataxias. J Neuropathol Exp Neurol 1999;58:748-64.

31 Sequeiros J, Coutinho P. Epidemiology and clinical aspects of MachadoJoseph disease. Adv Neurol 1993;61:139-53

32 Yuasa T, Ohama E, Harayama H, et al. Joseph's disease: clinical and pathological studies in a Japanese family. Ann Neurol 1986;19:152-7.

33 Kumada S, Hayashi M, Mizuguchi, et al. Cerebellar degeneration in hereditary dentatorubral-pallidoluysian atrophy and Machado-Joseph disease. Acta Neuropathol 2000;99:48-54. 